$\begin{array}{ll} & \text { Etnográfica } \\ \text { etnográfica } & \text { Revista do Centro em Rede de Investigação em }\end{array}$

Antropologia

vol. 15 (3) | 2011

Vol. 15 (3)

\title{
Alice Duarte, Experiências de Consumo: Estudos de Caso no Interior da Classe Média
}

\section{Filomena Silvano}

\section{OpenEdition \\ Journals}

Edição electrónica

URL: https://journals.openedition.org/etnografica/1091

DOI: 10.4000/etnografica.1091

ISSN: 2182-2891

\section{Editora}

Centro em Rede de Investigação em Antropologia

\section{Edição impressa}

Data de publição: 1 outubro 2011

Paginação: 607-609

ISSN: 0873-6561

\section{Refêrencia eletrónica}

Filomena Silvano, «Alice Duarte, Experiências de Consumo: Estudos de Caso no Interior da Classe Média», Etnográfica [Online], vol. 15 (3) | 2011, posto online no dia 23 outubro 2011, consultado o 12 fevereiro 2022. URL: http://journals.openedition.org/etnografica/1091 ; DOl: https://doi.org/10.4000/ etnografica.1091

Etnográfica is licensed under a Creative Commons Attribution-NonCommercial 4.0 International License. 
que essa escolha impõe. Por outro lado, ainda pode salientar-se que, mesmo que o autor fale da imigração brasileira no Porto, as experiências focam mais o ponto de vista do imigrante no masculino, salvo o caso das mulheres que socializam nos mesmos bares e que trabalham no mercado do sexo, mas essas não podem ser estendidas a todas as mulheres brasileiras.

Finalmente, os contributos mais interessantes do livro, especialmente por serem mais críticos, inovadores e comparativos e por não terem perdido atualidade, são o capítulo 5 e o anexo sobre o exotismo. Enquanto o capítulo 5 analisa a contemporaneidade da lusofonia, como fenómeno colonial por oposição ao "pós-colonial”, como coluna vertebral do pensamento luso (salvo

Alice Duarte

\section{EXPERIÊNCIAS DE CONSUMO: ESTUDOS DE CASO NO INTERIOR DA CLASSE MÉDIA}

Porto, U. Porto Editorial, 2009, 226 páginas.

\section{Experiências de Consumo: Estudos de Caso no} Interior da Classe Média foi publicado em 2009 e corresponde a uma parte da tese de doutoramento defendida pela autora, Alice Duarte, em janeiro de 2008. O trabalho de terreno que deu origem ao estudo decorreu entre 2002 e 2004. Em 2002 Alice Duarte publicou, nesta mesma revista, um texto intitulado "Daniel Miller e a antropologia do consumo" e, em junho de 2010 , um outro, também correspondente a uma parte da tese, intitulado "A antropologia e o estudo do consumo: revisão crítica das suas relações e possibilidades". Este mapeamento poucas exceções), e explica as hierarquias étnico-raciais vigentes em Portugal, o anexo apresenta uma análise comparativa muito interessante sobre a situação e posicionamento dos imigrantes brasileiros em outros contextos migratórios, como a Argentina, os Estados Unidos e o Japão, os quais mudam segundo os imigrantes sejam ou não exotizados, permitindo ao leitor entender melhor a posição dos brasileiros em Portugal.

Num balanço final, a qualidade da discussão e debate que Cárcere Público traz ao fenómeno das migrações, especialmente no contexto português, valoriza esta publicação tardia.

Beatriz Padilla

CIES-IUL temporal serve a tarefa de colocar a obra aqui recenseada no interior da produção antropológica nacional e internacional: no início da década de 2000 a autora faz uma aproximação teórica aos então recentes (mas já em clara fase de expansão para as academias de países periféricos) estudos do consumo em antropologia e inicia uma investigação que será publicada em livro no fim da mesma década (o segundo volume O Consumo para os Outros - foi publicado já em maio de 2011, também pela U. Porto Editorial). Este foi, grosso modo, o arco de tempo necessário para que o novo campo de estudo - investido por vários investigadores - tomasse forma em Portugal. A produção académica é hoje muito veloz, mas não prescinde dos tempos necessários à sua boa realização e estes parecem ser mais longos que aqueles que presidem ao funcionamento do real: neste caso, estamos face a uma obra indispensável para compreender 
a realidade portuguesa contemporânea, mas que já nos fala de um passado (que, dadas as circunstâncias, se transformou em algo dramaticamente longínquo).

Alice Duarte coloca-se de forma clara (e explícita) no interior de uma perspetiva analítica que, no seguimento da proposta de Daniel Miller, opta por deslocar os estudos sobre cultura material do polo da produção para o polo do consumo: "eleger o consumo como campo de pesquisa efetivo tem subjacente a rejeição de o olhar como mero resultado da produção ou, mais especificamente, do modo de produção capitalista, deslocando para o próprio consumo o foco e interesse da análise" (p. 7). No interior desse posicionamento mais geral, opta por concentrar-se nas dimensões mais micro da observação etnográfica - indivíduos e respetivas famílias -, de forma a trabalhar os mecanismos de produção/negociação das identidades pessoais e familiares: “[...] a análise compartimentou a realidade empírica e elegeu o papel do consumo em termos da produção de identidades particulares e em termos da criação e manutenção de redes de sociabilidades como alvos da sua atenção, fazendo emergir a tríade analítica consumo-identidade-sociabilidade" (p. 8). No que diz respeito às etapas do ciclo de consumo, a investigação centra-se nos mecanismos que, após a compra, integram os objetos no trabalho de construção de si levado a cabo pelas pessoas a quem passam a pertencer: "[...] a intenção central do atual texto é tornar manifestos e dar a conhecer processos de apropriação e respetivas atribuições de significado efetivos pelas pessoas concretas que são os consumidores-informantes" (p. 10).

Para responder às opções conceptuais mencionadas, o estudo empírico foi desenhado a partir de dois critérios: o primeiro prende-se com questões de estrutura social e o segundo diz respeito às etapas do "ciclo do consumo". As pessoas escolhidas integram o setor médio da sociedade portuguesa - são, segundo os parâmetros sociológicos, membros da "classe média" - e são "visitantes" do Norteshopping, um centro comercial situado na zona do Grande Porto. O primeiro critério visava criar um universo de estudo sociologicamente homogéneo, de forma a poder centrar a interpretação nas dimensões mais pessoais, fugindo assim, deliberadamente, ao estudo dos efeitos de estrutura: “[...] ou seja, em vez de se procurar uma assimilação estrita entre categorias de consumidores e categorias sociais de classe ou status, o consumo é aqui analisado enquanto meio útil - e utilizado - de expressão e comunicação de construções de valores e do sentido do que cada um é: um jovem, uma mãe de família, um amigo do peito, uma pessoa cosmopolita" (p. 8). Já o segundo homogeneizou o terreno em que se desenrola a etapa das "compras", para centrar a interpretação nas dinâmicas da etapa seguinte, a das "apropriações". Na prática, foram trabalhados 24 agregados familiares.

No meu entender, o desenho da pesquisa integra, de forma inteligente e eficaz, as dimensões empíricas e as dimensões conceptuais. A opção conceptual dependia, neste caso, do trabalho sobre as esferas mais delicadas de uma etnografia do consumo aquelas que por implicarem as vidas domésticas das pessoas as colocam mais a nu. Sem penetrar nessas dimensões não é possível entender as relações que estabelecemos com os objetos, ou as razões pelas quais eles constroem as nossas existências mais profundas. A obra de Alice Duarte consegue chegar a esse território delicado - e consequentemente consegue provar cabalmente a pertinência do seu estudo - sem nunca romper a película ténue que protege a dignidade das pessoas que aceitaram trabalhar com ela. O seu livro permite-nos assim perceber o quanto são - quando vistos a partir de escalas de análise micro - delicados e frágeis os mecanismos de construção identitária de 
uma classe média recentemente chegada a parâmetros de consumo já solidificados em outros países. No entanto, prescindir, na interpretação dos dados, da inserção dos efeitos de estrutura - "O objetivo de ilustrar o processo de consumo como atividade prática, moral e contextual específica beneficia, portanto, deste recurso a uma noção de estilo de vida que, mais do que entendido como instrumento de diferenciação social, procura remeter para tendências familiares fornecedoras de consistência interna às apropriações concretizadas pelos informantes" (p. 119) - enfraquece, no meu entender, as possibilidades de elucidação do real. A classe média portuguesa não é, sobretudo no que diz respeito às suas origens, homogénea, e por isso os mecanismos que decorrem das posições que as pessoas ocupam na estrutura social, nomeadamente os de "distinção" social, estão nela presentes. Mas, apesar deste reparo, o trabalho consegue esclarecer questões que se prendem com as dinâmicas familiares específicas e questões de caráter mais estrutural. Fica claro que naquele tempo, o início do século XXI, a classe média portuguesa pensava que

Kesha Fikes

MANAGING AFRICAN PORTUGAL Chapel Hill, NC, Duke University Press, 2009, 195 pages.

Managing African Portugal by US anthropologist Kesha Fikes is an ethnographic account of how Portugal's mid-1990s economic and social integration into the European Union (EU) fundamentally changed everyday encounters between Portuguese citizens and African immigrants. Fikes' book is a thoughtful assessment of how colonial legacies tinha chegado, finalmente - com euforia, esforço e por vezes sofrimento - à "sociedade de consumo". Para um cientista social conhecedor dos estilos de vida de outras classes médias, era evidente que não era bem assim: a ausência dos consumos culturais - colocados no pacote das coisas dispensáveis, senão mesmo das inúteis - era o sintoma mais óbvio da falta de consistência temporal dessa nova classe média (estavam lá as mesmas coisas - carros, aparelhagens, relógios - mas não estavam lá os mesmos conteúdos - construídos nas universidades, nos museus e nos teatros). Agora que tudo foi posto em causa, a evidência da distância que nos separa dos parâmetros do consumo médio europeu obriga-nos, seguindo mais uma vez as tendências reveladas pelos trabalhos recentemente produzidos nas academias com maior visibilidade internacional, a reequacionar as relações complexas que se estabelecem, no interior de novos quadros macroeconómicos, entre as esferas da produção e as esferas do consumo.

\section{Filomena Silvano}

CRIA/FCSH-UNL

impact contemporary social relations in an EU context and is a poignant critique of how government-sponsored "multiculturalist" programs can increase the marginality of the people they purport to help. She records the roughly fifteen years of "Europeanization" in Portugal, a period defined by "modernization," profound shifts in the job market, and changing attitudes towards race. During this time, Portugal ceased to be a country from which people left, but instead became a "country of immigration," a shift corroborated by the visibility of African migrants. 